\title{
Impact of Swear and Negative Texts on Social Media Users
}

\author{
Srishty Jindal, S.V.A.V. Prasad, Kamlesh Sharma
}

\begin{abstract}
Nowadays, the use of social media has increased exponentially. People show different behavior on social media depending on the kind of responses and behavior of people around them. It is important now to analyze the behavior of social media users and the way how they affect their friends. In this paper, behavioral analysis of people is done based on Twitter data. An algorithm is proposed which helps in finding the impact of text written by someone on social media and its effect on others. The impact of written text is calculated with the help of the number of retweets done for the same tweet. The severity of the used word is calculated based on AFINN dictionary. According to the proposed algorithm, the score of the dictionary is recalculated when a negative word is forwarded multiple times. This is done with the understanding that if a less severe negative word is used many times, it may affect the person in a highly negative manner. With this, Severity of words is recalculated and its impact on people is found with the help of the proposed algorithm. The impact of using negative words on social media affect $32 \%$ of the total users (in their friend-list). Behavior change is demonstrated with the help of graphs week-wise, month-wise and year-wise analyses. The research helps in finding the impact of swear words on social media users depending on the frequency and severity score of the words.
\end{abstract}

Keywords: social media, negative text, tweets, behavioral analysis

\section{INTRODUCTION}

$\mathrm{W}_{\text {ith }}$ the hasty increase in the use of multimedia and mobile phones, people are getting attached to gadgets like never before. It includes excessive use of the mobile phone for different purposes. Nowadays mobile phones are not limited to calls instead, a lot more can be done with their help. People get connected with their friends using social media. They prefer to communicate through social media on any topic of their interest. Social media connect people worldwide and helps in sharing information. This shared information is not kept secret usually and is further shared with the chain of friends. This sharing of information makes a chain and affects all the people included in the chain differently. This effect of information depends on the mood of the person.

Manuscript received on 2 October 2021 | Revised Manuscript received on 19 October 2021 | Manuscript Accepted on 15 November 2021 | Manuscript published on 30 November 2021. *Correspondence Author

Srishty Jindal*, Research Scholar, Lingaya's Vidyapeeth, Assistant Professor, CSE, FET, Manav Rachna International Institute of Research and Studies, Faridabad, Haryana, India. Email: srishtyjindal@gmail.com1

Dr. S.V.A.V. Prasad,. Prof, EEE Department., Lingaya's Vidyapeeth, Faridabad, Haryana, India. Email: svavprasad@lingayasvidyapeeth.edu.in

Dr. Kamlesh Sharma, Associate Professor, CSE, FET, Manav Rachna International Institute of Research and Studies, Faridabad, Haryana, India. Email: kamlesh.fet@mriu.edu.in

(C) The Authors. Published by Lattice Science Publication (LSP). This is an open access article under the CC-BY-NC-ND license (http://creativecommons.org/licenses/by-nc-nd/4.0/)
The messages float on social media may have a positive, negative, or neutral meaning. This is called the sentiment of the sentence and analysis of such sentences is called sentiment analysis. If the sentiment of a sentence is negative, it also affect people negatively and changes the behavior of the user momentarily. In this paper, research is done in the area where social media users are affected by the text written on social media. The analysis is done week-wise for the whole one year. 100 users were selected to analyze based on the frequency of the text and the score of the negative words used by the person. From the study, it is found that approximately 63 percent of the users are affected by the words written by someone in their friend list. Out of these users, approximately 32 percent of users are affected (shows interest) negatively and share the same in their respective groups. This research is done on Twitter data collected through Twitter API. The proposed algorithm works on the count of retweets done for a particular tweet.

\section{BACKGROUND}

In this research, the author focussed on social media use and its effect on mental health [1]. Excessive use of social media may lead to anxiety, depression, stress and may impact the mental health of a person (if used adversely). Various studies have shown that there is a direct relationship between the use of social media and the compulsive behavior of a social media user. In research done in Britain, it was found that approximately $45 \%$ of them feel impatient if in case they are not able to use social networking sites. Rosen et al. [2] researched on behavior shown by the younger generation. This research also resulted in findings on feeling restlessness in case they do not have access to their social media application messages, this gives rise to a syndrome called Phantom Vibration Syndrome (PVS). PVS is the perception of an addicted person regarding vibration of the cell phone [3]. Rothberg et al. [4] researched that any person who imitates PVS behavior reflects obsession of frequent checking of social messages which also portrays an indication of anxiety caused by mobile phones. The use of social media increases the stress level of a person in today's world. Once a person gets on, it becomes very difficult to abstain from its usage. People compare their lives with the lives of their social media friends which also leads to a stressful life. Comments and likes on social media act as a positive fortification and make its use more addicted. Dick J. [5] reported that because of the free usage of social networking sites such as. Facebook and Twitter, people remain associated with their friends and read some useful content but at the same time, they lose a lot of discretion and confidentiality. This leads to anxiety which is one of the major health problems.

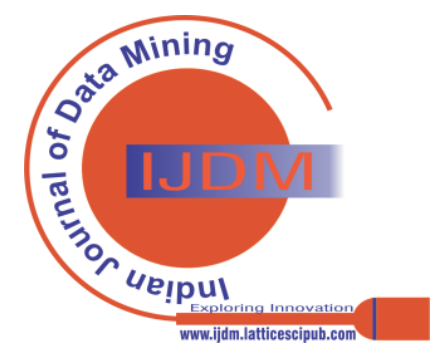




\section{Impact of Swear and Negative Texts on Social Media Users}

People fuss about the comments and likes on the pictures and videos shared by them on social media. In research, The Heartly Soul [6] emphasizes that students who spent more time on Social Networking sites such as Facebook and Twitter are less focused and more stressed than others. According to the study if more time is spent on social media, the more depressed the user will be [7]. Kaur and Bashir [8] discovered the positive and negative affect of social media on its users. The positive effects are related to the learning opportunities, socialization, communication, and access to health information. Whereas negative effects include stress, depression, cyber bullying, emotional breakdown, online harassment and decline of intellectual ability. Nowadays, almost all the people are connected to social media. Young adults are the most active users and prominently at a very high risk of developing mental issues at a very high rate [9]. This is a matter of concern here. Park et al. [10] conducted a study and find that some social networking sites (Facebook) are causing acculturative stress in college students. Kaur and Bashir [8] also done exploration on the effect of stress on the mental health of students and find that stress negatively affects the mental health of individuals. It is concluded that excessive use of social media leads to a bad effect on the mental health of social media users. Apart from stress, continuous use of social media encourages mental health problems and further leads to anxiety which in further may cause depression also. Pantic et al. [11] exposed a positive relationship between time spend on social media and depression. In Rosen et al. [2], figured that people who spend most of their time on social media show the symptoms of major depression. Lou et al. [12] reported that students who excessively use Facebook are more prone to loneliness. Continuous use of social media is a reason for Psycho-social problems like tunings and confidence [13]. Davila et al. [14] imitated that the young generation shows more negative and less positive social interactions on social media and hence reflects severe depression symptoms. In contrast to this research, Kraut et al. [15] researched the inverse relationship between internet usage and depression. According to this research, they suggest that few activities like gaming and chatting on the internet lowers the risk of depression. Social Relationship plays an important role in keeping mental health (Mental Health Foundation). According to Umberson \& Montez et.al. [16], the quality and quantity of any social relationship affect the psychological well-being, behavior, corporal health, and impermanence risk of a person. Many experimental studies found that social livelihood can improve people's lives and can suppress loneliness [17], prevent hopelessness [18], strengthen positive states of mind [19] and demoralize avoidant coping. On the other hand, depression is caused by negative social interactions and social isolation [20], [21], which also leads to suicidal results [22]. Reich et al. [23] engrained social interaction with better mental health. A social relationship helps in building positive behavior and helps in maintaining good mental health. Worthy support from friends and relatives on social media relieves a person from mental health problems even after any tragic event [24]. All the research done so far is focused on finding the effect of social media on the mental health of people using text and the behavior of the user. All this calculation shows the same impact of words on all users. But this is not the actual case. People with different mindset are affected differently. The algorithm in research shows how the complete behavioral analysis of a person is analyzed on social media by using behavioral and structural features [25]. Analysis of structural features is done with the help of natural language understanding [26].

\section{PROPOSED METHODOLOGY}

The proposed methodology helps in determining the effect of the use of negative words and their spread on social media. Research being done on social media shows concern about the text shared among social media users. The effect of negative words is different on different people depending on their moods and state of mind. It is not fair to consider the impact of negative words, same to all people. The effect and reaction of people are analyzed by analyzing their behavior on the social platform. Accordingly, people who further share such text carry a similar kinds of interests. People who do not show interest in such events, usually ignore such text and do not react to them or even report them to the admin. Considering the situation, an algorithm is proposed which calculates the sentiment score of any text depending on the number of times it is shared. The steps used in finding the effect of negative words on social media users are shown in Fig. 1.
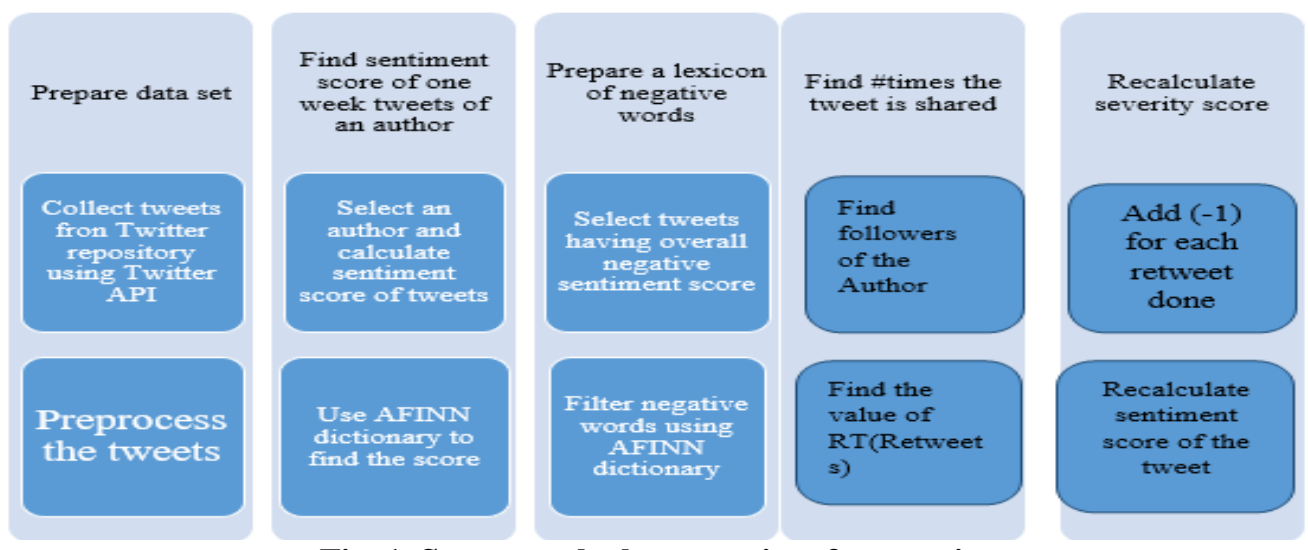

Fig. 1. Steps to calculate severity of a negative text

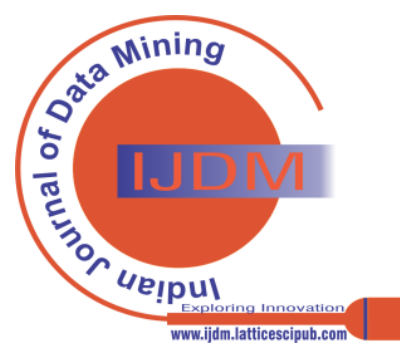


The overall procedure includes five major steps. To apply the algorithm, tweets are collected using Twitter API. To filter relevant data, pre-processing is done such as stemming, removal of stop words, lemmatization. Initially consider the tweets of one week only as the analysis is done week-wise. Filter the words which are used in tweets after the removal of irrelevant words. Use AFINN dictionary to calculate the sentiment score of tweets. The sentiment score of a tweet will indicate whether the tweet done is negative, positive, or neutral. Consider only negative tweets and prepare a lexicon of negative words only. Once the lexicon is prepared, further use of such words can be identified. Once the shared text of an author is analyzed, find its followers and perform the same analysis. For each negative tweet count the number of RT (Retweets) in front of the tweet. Consider the RT count in recalculating the severity score of the tweet.

The algorithm proposed to find the impact of tweets done by a person on their followers is:

1. Let $\mathrm{A}$ is the author-ID.

2. Calculate sentiment score of all the tweets done by A in one week.

3. Find tweets having overall sentiment score $<0$.

4. For all such tweets //Prepare a list of negative words

a. Extract words ' $\mathrm{W}$ ' from tweet.

b. For all $(\mathrm{w} \in \mathrm{W})$

i. Find AFINN score 'A $\mathrm{A}_{\text {score }}$ ' of the word

ii. If $\left(\mathrm{A}_{\text {score }}<0\right)$ add word in the list L.

5. Find the followers of A. Calculate value of RT (Retweets) for all the followers $\mathrm{F}$ for the same tweets extracted above.
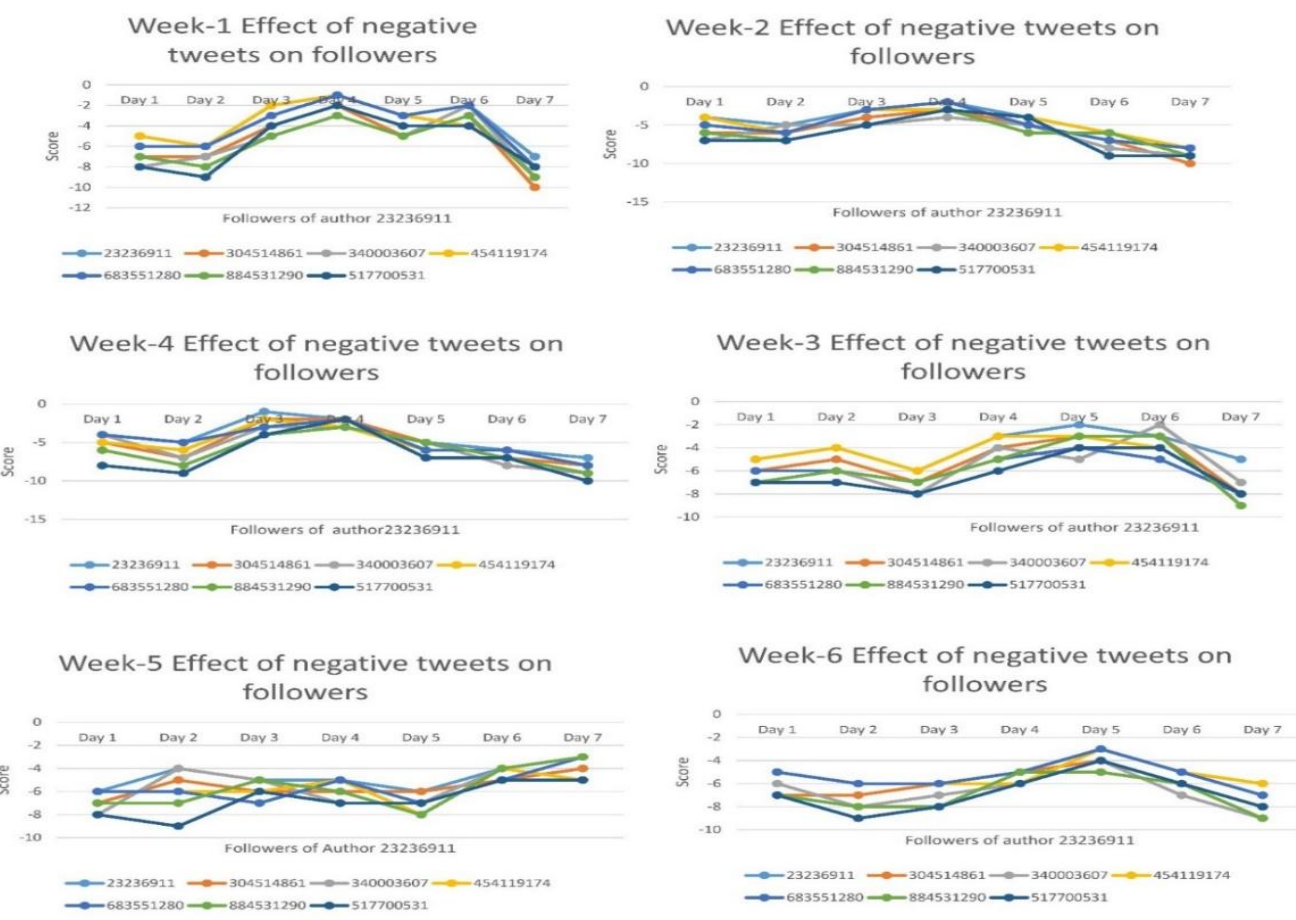

Fig. 2. Demonstrates the week-wise analysis of followers of author-id 23236911. a. Calculate impact score of followers $\mathrm{f}^{\mathrm{i}}$

i. $\mathrm{f}_{\text {score }}^{\mathrm{i}}=\mathrm{A}_{\text {score }}^{\mathrm{i}}+(-1)$

8. Return $\mathrm{f}^{\mathrm{i}}, \mathrm{f}_{\text {score }}^{\mathrm{i}}$

of an author.

\section{RESULT AND ANALYSIS}

Tweets were collected from Twitter using Twitter API. The data set consists of 254678 tweets. These tweets were collected for the whole 1 year. To fetch the tweets, 76 hashtags were selected. These hashtags were selected using should not be used publicly.

To analyze the complete behavior of an author, the analysis was initially done on day to day basis. The tweets were ered according to date and an analysis of one week was week-wise analysis is shown in the graphs. Six graphs of six weeks are shown in the figure 2. From the graph it is , there are times when people show a negative sharing it with more users.

The analysis in Fig. 2 shows the behavior of followers of the or for use of negative words only. For this analysis, only behavior of followers is intended by calculating the number of shares and retweets. Further, this analysis is done monthwise and then finally for a year.

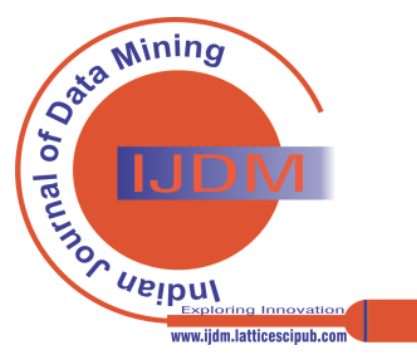




\section{Impact of Swear and Negative Texts on Social Media Users}

\section{A. Month-wise Analysis}

The original screen names are not used here to show the result for security reasons. Eight digit IDs were created for all the users whose analysis is done. [Fig. (3a)] depicts the month-wise analysis of 6 followers of 23236911. This analysis is done for 4 weeks (one month). Similarly, behavior is analyzed for the whole one year as shown in
[Fig. (3b)]. From the curves of the graph, it is easier to find the mood swing of the person while using social media. The place where all the lines showing the same curves means people are in a similar mood at this time. There may be a common reason to show the same mood which could be analyzed with the help of shared text on social media.
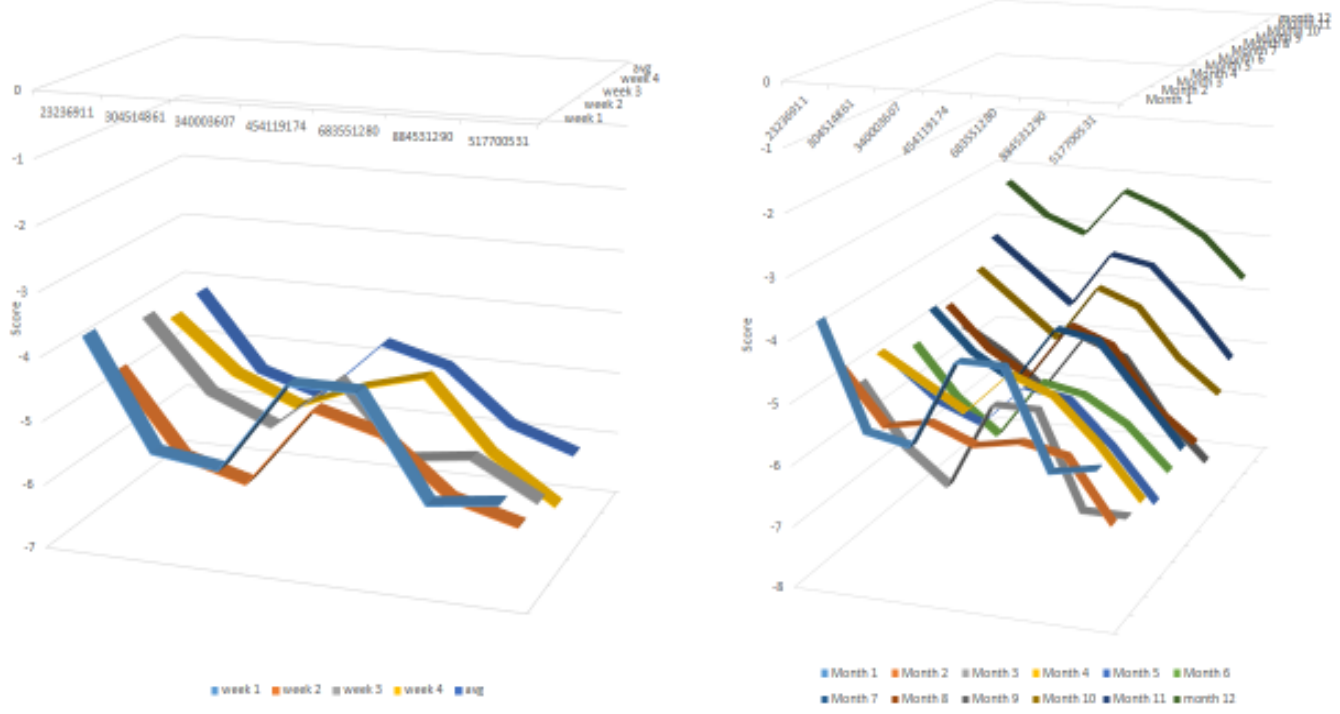

Fig. 3a) Month wise analysis of followers of Author 23236911 Fig. 3b) Yearly analysis of followers of author 23236911

\section{B. Complete behavioral analysis of the author}

The complete behavioral analysis of an author (along with its followers) is done based on the tweets posted by the author in one year [Figure 4]. This analysis includes all the positive and negative thoughts shared by the person on social media. A complete analysis of behavior is shown in the graph. The pointed edges show the ups and downs in the behavior of a person. The analysis was done on all ages of people and found that $32 \%$ of the social networking users (followers) are being affected by the negative behavior of their friends on social media. The change in their behavior is noticed by $5 \%$ of their friends and family.

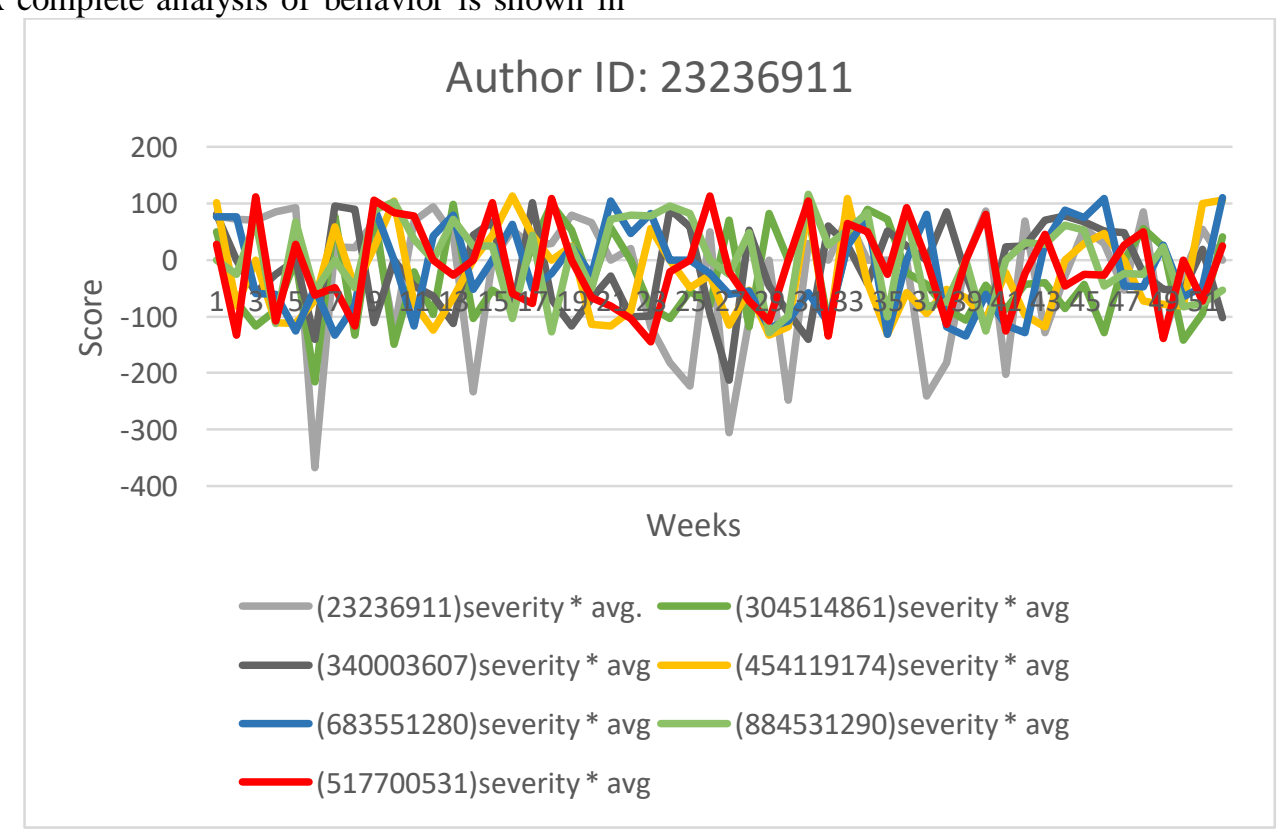

Fig. 4: Behavioral analysis of an author on Twitter

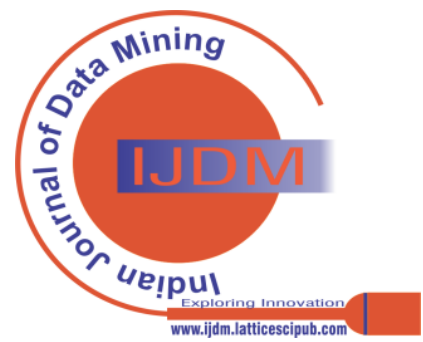


The result shows behavior analysis of 3 authors. The behavior of their followers is also analyzed with the same algorithm. The analysis is done with the help of tweets shared by the person on Twitter. There were 12 followers of Author 23236911 whose behavior is analyzed. Out of which, 6 are considered based on maximum involvement. Behavioral change is reflected by peaks in the graph (Fig. 4). Table 1 shows the effect of negative text written by a particular person on social media, among its followers.

Table I: Behavioral Analysis on followers

\begin{tabular}{|c|c|c|}
\hline \multirow{2}{*}{ Author ID } & \multicolumn{2}{|c|}{ Impact of social media } \\
\cline { 2 - 3 } & $\begin{array}{c}\text { \#Total Followers } \\
\text { considered }\end{array}$ & \#followers effected \\
\hline 23236911 & 43 & 12 \\
\hline 33345956 & 62 & 15 \\
\hline 48207152 & 72 & 27 \\
\hline
\end{tabular}

\section{CONCLUSION}

The research has been done to avoid the unscrupulous effect of using social media these days. People use words which spread negative impact like abuses, taunts, swear words, and these are further circulated to many people directly or indirectly through channels, pages, and forums on social media platforms. To find the effect and intensity of such texts and their effects, an algorithm is proposed. This algorithm helps determine the negative words and their effect on people in different manners. AFINN dictionary is used to find the severity of the subjected negative word. For instance, if a negative word with a low severity level is used multiple times, its effects also get multifold yielding alarming results. The proposed algorithm in this research recomputes the value of the same negative word based on the number of times it is forwarded/used/spread on a similar platform and hence determines the increase in a negative score. This will imply that there are texts/words/phrases with negative impacts and nature floating on social media and needs to be alarmed and reported to the admins. Further spread of such messages should be avoided on social media with immediate effect.

\section{REFERENCES}

1. H. Bashir and S. A. Bhat, "Effects of Social Media on Mental Health: A Review," Int. J. Indian Psychol., vol. 4, no. 3, pp. 125131, 2017. [CrossRef]

2. L. D. Rosen, K. Whaling, S. Rab, L. M. Carrier, and N. A. Cheever, "Is Facebook creating 'iDisorders'? The link between clinical symptoms of psychiatric disorders and technology use, attitudes and anxiety," Comput. Human Behav., vol. 29, no. 3, pp. 1243-1254, 2013. [CrossRef]

3. M. Drouin, D. H. Kaiser, and D. A. Miller, "Phantom vibrations among undergraduates: Prevalence and associated psychological characteristics," Comput. Human Behav., vol. 28, no. 4, pp. 1490 1496, 2012. [CrossRef]

4. M. B. Rothberg, A. Arora, J. Hermann, R. Kleppel, and P. Visintainer, "Phantom vibration syndrome among medical staff: A cross sectional survey," BMJ, vol. 341, no. 7786, pp. 1-4, 2010 [CrossRef]

5. Dick J, "Why Do Social Networks Increase Stress ?," The Huffington Post, 2016. [Online]. http://www.huffingtonpost.in/entry/social-networks-andstress_b_3534170,2013.

6. The Heartly Soul, "Using Social Media is Causing Anxiety, Stress and Depression," 2016. [Online]. Available: http://theheartysoul.com/mental-health-risks-of-social-media/, 2016.

7. A. Singh, H. Kumar, and S. Kumari, "Impact of social media on adolescent's mental health," in International Journal of Creative Research Thoughts, no. 7, 2020, pp. 2320-2882.

8. R. Kaur and L. Bashir, "Impact of stress on mental health of students: Reasons and Interventions," Int. J. Educ., vol. 5, no. 30-35, 2016.
9. A. Strickland, "Exploring the effect of social media use on the mental health on young adults," 2014

10. N. Park, H. Song, and K. M. Lee, "Social networking sites and other media use, acculturation stress, and psychological well-being among East Asian college students in the United States," Comput. Human Behav., vol. 36, pp. 138-146, 2014. [CrossRef]

11. I. Pantic et al., "Association between online social networking and depression in high school students: Behavioral physiology viewpoint," Psychiatr. Danub., vol. 24, no. 1, pp. 90-93, 2012.

12. L. L. Lou, Z. Yan, A. Nickerson, and R. McMorris, "An examination of the reciprocal relationship of loneliness and facebook use among first-year college students," J. Educ. Comput. Res., vol. 46, no. 1, pp. 105-117, 2012. [CrossRef]

13. M. Kalpidou, D. Costin, and J. Morris, "The relationship between facebook and the well-being of undergraduate college students,' Cyberpsychology, Behav. Soc. Netw., vol. 14, no. 4, pp. 183-189, 2011. [CrossRef]

14. J. Davila, R. Hershenberg, B. A. Feinstein, K. Gorman, V. Bhatia, and L. R. Starr, "Frequency and quality of social networking among young adults: Associations with depressive symptoms, rumination, and corumination.," Psychol. Pop. Media Cult., vol. 1, no. 2, pp. 72 86, 2012. [CrossRef]

15. R. Kraut, M. Patterson, V. Lundmark, S. Kiesler, T. Mukophadhyay, and W. Scherlis, "Internet paradox: A social technology that reduces social involvement and psychological well-being?," Am. Psychol., vol. 53, no. 9, pp. 1017-1031, 1998. [CrossRef]

16. D. Umberson and J. Karas Montez, "Social Relationships and Health: A Flashpoint for Health Policy," J. Health Soc. Behav., vol. 51, no. 1_suppl, pp. S54-S66, 2010. [CrossRef]

17. S. G. Schneider, T. S. E., H. C., M. Kemeny E., and J. Dudley, "Factors influencing suicide intent in gay and bisexual suicide ideators: Differing models for men with and without human immunodeficiency virus," J. Pers. Soc. Psychol., vol. 61, no. 5, pp. 776-788, 1991. [CrossRef]

18. J. G. Johnson et al., "Hopelessness as a mediator of the association between social support and depressive symptoms: Findings of a study of men with HIV," J. Consult. Clin. Psychol., vol. 69, no. 6, pp. 1056-1060, 2001. [CrossRef]

19. J. S. Gonzalez et al., "Social support, positive states of mind, and HIV treatment adherence in men and women living with HIV/AIDS," Heal. Psychol., vol. 23, no. 4, pp. 413-418, 2004. [CrossRef]

20. T. L. Schuster, R. C. Kessler, and R. H. A. Jr., "Supportive interactions, negative interactions, and depressed mood," Am. J. Community Psychol., vol. 18, pp. 423-438, 1990. [CrossRef]

21. K.-L. Chou, K. Liang, and J. Sareen, "The Association Between Social Isolation and DSM-IV Mood, Anxiety, and Substance Use Disorders: Wave 2 of the National Epidemiologic Survey on Alcohol and Related Conditions," J Clin Psychiatry, vol. 72, no. 11, pp. 1468-1476, 2011. [CrossRef]

22. K. M. Holma, T. K. Melartin, J. Haukka, I. A. K. Holma, T. P. Sokero, and E. T. Isometsä, "Incidence and predictors of suicide attempts in DSM-IV major depressive disorder: A five-year prospective study," Am. J. Psychiatry, vol. 167, no. 7, pp. 801-808, 2010. [CrossRef] 


\section{Impact of Swear and Negative Texts on Social Media Users}

23. R. WA, L. DW, Z.-M. S, and R. BD, "Forms of social support and their relationships to mental health in HIV-positive persons," Psychol Heal. Med., vol. 15, no. 2, pp. 135-145, 2010. [CrossRef]

24. P. K. Maulik, W. W. Eaton, and C. P. Bradshaw, "The effect of social networks and social support on mental health services use, following a life event, among the Baltimore epidemiologic catchment area cohort," J. Behav. Heal. Serv. Res., vol. 38, no. 1, pp. 29-50, 2011. [CrossRef]

25. S. Jindal and K. Sharma, "Intend to analyze Social Media feeds to detect behavioral trends of individuals to proactively act against Social Threats," Procedia Comput. Sci., vol. 132, pp. 218-225, 2018. [CrossRef]

26. S. Jindal and K. Sharma, "A review on sentiment classification: Natural Language Understanding," Recent Patents Eng., vol. 13, no. 1, pp. 20-27, 2019. [CrossRef]

\section{AUTHOR'S PROFILE}

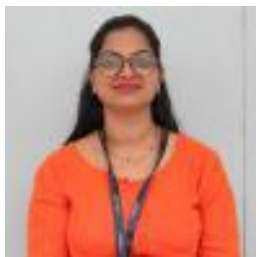

Srishty Jindal, is Research Scholar at Lingaya's Vidyapeeth and working as Assistant Professor in Department of Computer science and engineering, Faculty of Engineering and Technology, Manav Rachna International Institute of Research and Studies, Faridabad, India. She received B.Tech (Ccomputer Science and Engineering) degree in 2006 and M.tech (Computer Science and Engineering) in 2009 from Maharishi Dayanand University, Rohtak. Her current research focused on Natural Language Processing, Data mining, Operating System and artificial Intelligence. She published and presented 7 refereed articles is prestigious venues such as IEEE, Elsevier etc. She is also a member of ICSES research community. She is a result oriented, proactive and focused professional with around 14 years of diversified work experience with special emphasis on the areas database management system, operating system, software engineering and many more. Adopted innovative teaching methodology like role play, case studies, simulation, presentations, live projects, smart classrooms technologies and combined these with regular lecture method to make the overall teaching learning process more effective.

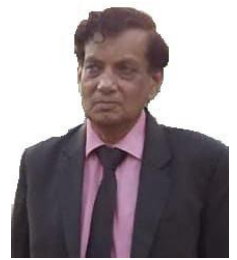

Dr. S.V.A.V. Prasad, did his M.Tech and Ph.D (Satellite Communications).Presently working as professor, Dean ( CA) and Director Lingaya's Vidyapeeth, Faridabad, Haryana. Dr. Prasad has developed various products like $100 \mathrm{MHz}$ dual Oscilloscope, High Voltage Tester, VHF Wattmeter, Standard Signal Generator with AM/ FM Modulator, Wireless Becon, High power audio Amplifier, Wireless microphone and many more in the span of 25 years( 1981-2007). Dr. Prasad has been awarded for excellence in R\& D in the years 1999, 2004 and National Quality Award during the Years 1999, 2000, 20042006. He has over 40 years of active professional, Research and Administrative experience both in Industrial and Academics in senior positions. Dr. Prasad has guided 28 research scholars and they were awarded Ph.D degree. Presently guiding eight $\mathrm{Ph}$. D Scholars in the Research Areas of Communication Engineering, thermal image processing for early diagnose of breast cancer, medical facilities for remote areas using m-health solutions, thought processing gadgets adoptive for broad band wireless communication and Semantic Web, Information Retrieval and so on. Dr. Dr. Prasad has published 168 research papers in various National and International ,referred journals such as SCL, IEEE, Springer, ACM etc and also published text volumes. Dr. Prasad's research area includes Satellite Communication , Acoustics, Neural Networks, Artificial Intelligence and m health. Dr. Prasad is a Fellow member ,Institute of Electronics \& Electrical Engineering ( IEEE), corporate member Indian Productivity Council, Corporate member Elicina, Executive member Calibration and Standardization, ( ERTL, HRTL, HSL) etc. Life member ISTE, IETE, Society of Audio and Video systems. Actively associated with the Institution of Engineers for the past twenty three years , Advisory Board Member in Technical exams Committee, Reviewer of International and National journal Articles, Actively participated and organized refresher courses, Seminars, workshops for ISO, ROHS, AI, WEEE, Product Standardization Methods, Time study, Production Enhancement, technology transfer and project feasibility methods. Dr. Prasad is an active participant in social service and conducted may conferences, seminars, workshops in m health related programmes. He always believes in team work for progressive and effective results.

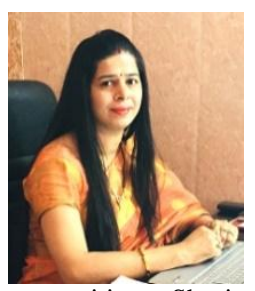

Dr. Kamlesh Sharma, is currently working as a Associate Professor, MRIIRS, Faridabad, India (more than 14 years teaching experience). MCA, M. Tech from MDU University and Ph. D. in Computer Science and Engineering from Lingaya`s Vidyapeeth, India. is currently Supervising five Ph. D. scholars. She has also supervised and guided research projects of $M$. Tech, B.Tech and application based projects for different competitions. She is also associated with four Govt. research projects in filed of health recommender system, IOT, Machine Learning, AI and NLP. She has published more than 45 research papers in field of NLP, IOT, Bigdata, Green Computing and Data Miningin reputed Journal (Web of Science, Scopus, UGC, Elsevier) and Conferences (ACM, IEEE). Her research area "Natural Language Processing" is based on innovative idea of reducing the mechanized efforts and adapting the software to Hindi dialect. She is associated with various professional bodies and renowned journals in varied capacities viz. CSI (Computer Society of India), Member, International Journal of Computer Networks and Applications (IJCNA) as Editoral Board Member, BJIT - BVICAM's International Journal of Information Technology, ISSN 0973 - 5658, Springer Index as Reviewer, International Journal of Computer Science and Information Security (IJCSIS), Google Scholar Index as Reviewer \& Editorial board member, International Journal of Science \& Engineering Development Research IJSDR, UGC Approved Journal, Google Scholar Index as Member of referral/ review Management System. Adopted innovative teaching methodology like role play, case studies, simulation, presentations, live projects, smart classrooms technologies and combined these with regular lecture method to make the overall teaching learning process more effective.

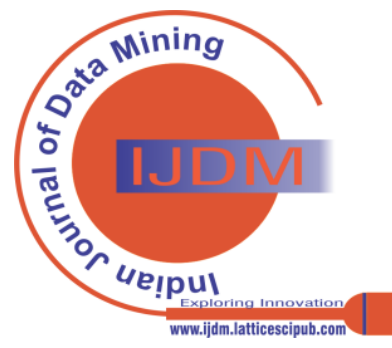

